Journal of Environmental Assessment Policy and Management

Vol. 20, No. 3 (September 2018) 1840003 (28 pages)

(C) The Author(s)

DOI: $10.1142 / \mathrm{S} 1464333218400033$

\title{
Spatial Multi-Criteria Decision Analysis Tool Suite \\ for Consensus-Based Siting of Renewable Energy Structures
}

\author{
Frank Hanssen*, Roel May ${ }^{\dagger}$ and Jiska van Dijk ${ }^{*}$ \\ Norwegian Institute for Nature Research (NINA) \\ P. O. Box 5685 Torgard, No-7485 Trondheim, Norway \\ *Frank.Hanssen@nina.no \\ †roel.may@nina.no \\ tjiska.van.dijk@nina.no \\ Jan Ketil Rød \\ Department of Geography \\ Norwegian University of Science and Technology (NTNU) \\ No-7491 Trondheim, Norway \\ jan.rod@ntnu.no
}

Received 9 January 2018

Revised 28 June 2018

Accepted 27 July 2018

Published 11 September 2018

\begin{abstract}
Expansion of renewable energy development causes concerns which traditional land-use planning may have limited capacity to address adequately. The complexity and multiplicity of scales, criteria and actors involved in decision-making processes requires a holistic approach that captures the variety in stakeholder interests. Reaching consensus across interests ensures democratic and cost-effective decision-making processes. The Consensusbased Siting (ConSite) tool suite was developed for optimal siting of onshore wind-power plants and routing of high-voltage power lines considering stakeholder interests. ConSite is based on the operational steps of spatial multi-criteria decision analysis using a bottom-up holistic approach. Its spatially explicit graphical user interface allows for a high level of
\end{abstract}

*Corresponding author.

This is an Open Access article published by World Scientific Publishing Company. It is distributed under the terms of the Creative Commons Attribution 4.0 (CC-BY) License. Further distribution of this work is permitted, provided the original work is properly cited. 


\section{F. Hanssen et al.}

stakeholder involvement and includes inherent capabilities of scenario modelling. ConSite thereby helps to structure decision problems, balance conflicting interests and identify relevant decision strategies based on risk assessment and trade-off analysis. ConSite visualises the spatial consequences of implementing various decision strategies and balancing site-specific conflict levels with energy production potential.

Keywords: GIS; SMCDA; optimisation; spatial planning; renewable energy siting.

\section{Introduction}

Renewable energy is an essential measure for climate change mitigation. Hence, a rapid and large-scale development of renewable energy technology is pivotal to substitute carbon-based energy sources. However, as new renewable energy technologies continue to be deployed, it is increasingly important to acknowledge the effects these technologies may have on the natural environment and society. Although there is considerable support for renewable energy development, its expansion also causes several concerns, which traditional land-use planning may have limited capacity to address adequately. The negative impacts of renewable energy production on the environment and societies often become one of the main issues when new renewable energy structures (e.g. wind-power plants and highvoltage power lines) are planned, often leading to prolonged consent application processes (IPCC, 2011; Wolsink, 2012). Such conflicting issues may cause financial problems for the energy industry and for society as a whole (Cole, 2011) and reduce the predictability of the spatial planning and consenting processes. Therefore, there is a clear need for new, comprehensive and inclusive decisionmaking processes to avoid negative impacts during the planning phase (May, 2017). Conceptually, this requires a structured, iterative process of 'robust decision-making' (Lempert and Collins, 2007; Rist et al., 2013) to reduce uncertainty and to increase trust in the consenting decisions. The complexity and multiplicity of scales, criteria and actors involved in decision-making processes, however, requires a holistic approach that captures the variety in stakeholder views and perspectives (technological, socio-economic and environmental). Implementing a place-based social-ecological-technical system concept (Ostrom, 2009; McGinnis and Ostrom, 2014) allows us to consider the intricate linkages between environmental impacts, landscape and resource utilisation and the complexity of social acceptance of renewable energy development (McLachlan, 2009) and the inherent environmental, aesthetic and socio-economic dimensions (Enevoldsen and Sovacool, 2016). In short, there is a need for an improved planning and decision support tool that ensures democratic and cost-effective processes securing qualified decision-making (Wolsink, 2007; Mateo, 2012). 
Siting of wind-power plants, and the accompanying routing of high-voltage power lines, is a spatially explicit process based on multiple criteria (Fargione et al., 2012; Araneo et al., 2015) preferably derived through stakeholder involvement (Thygesen and Agarwal, 2014). Commonly included criteria for siting or routing are: connectivity to the electricity transmission grid and the identification of suitable corridors for power-line routing (Luthi and Prassler, 2011; McWilliam et al., 2012), turbine noise propagation and turbine/power line visibility in the landscape (Pedersen et al., 2009; Molnarova et al., 2012), property values (Zangl et al., 2008) and hotspots for birdlife (e.g. Bright et al., 2008; Tellería, 2008; Carrete et al., 2012; Liechti et al., 2013). Such exercises to support decision-making are predominately performed using Geographical Information Systems (GIS) and/or engineering tools specifically designed for the purpose. In regional planning, however, environmental and societal concerns of renewable energy development and transmission lines need somehow to be offset against technological and socioeconomic benefits within a spatial context. Spatial multi-criteria decision analysis (SMCDA) tools can help to identify suitable development areas and render feedback on the conflict potential and its inherent conflict levels. Several decisionsupport systems have been developed using GIS, employing both expert-based (Voivontas et al., 1998; Aydin et al., 2010; van Haaren and Fthenakis, 2011) and participatory approaches (Baban and Parry, 2001; Ramirez-Rosado et al., 2008; Gorsevski et al., 2013; Tsoutsos et al., 2015). GIS-based tools for multi-criteria analysis enable planners and decision-makers to prioritise among alternative strategies, thereby avoiding potential conflicts and enabling a more inclusive and transparent planning process (Simao et al., 2009; Ciaccia et al., 2010). Currently, most of these tools lack, however, the flexibility to vary their criteria sets. Although relevant criteria sets can be justified, these may simultaneously vary by country or region. Using a fixed set of criteria may hamper the stakeholder dialogue processes if some criteria are missing or considered irrelevant. Although regulations define minimum requirements for criteria inclusion and restriction areas (e.g. protected areas and urban areas), relevant criteria need to be identified and weighed by relevant stakeholders to enhance transparency and to reduce conflict levels.

SMCDA is an established approach to tackle complex and inclusive decisionmaking processes with a rich body of literature (Malczewski, 2006a; Afshari and Yusuff, 2012; Malczewski and Rinner, 2015; Schafer and Gallemore, 2016). The development of multi-criteria decision theory was from its beginning characterised by the methodological principle of multi-criteria decision-making. Although multicriteria problems sometimes are presented as a classical optimisation problem, the conception of an 'optimal' solution is recognised as having limitations. One limitation is that most criteria considered in decision-making are of non-linear 


\section{F. Hanssen et al.}

nature (Piegat and Sałabun, 2012). Another limitation is that it is impossible to optimise all criteria at the same time. Instead, decision theory teaches us to look for 'compromise solutions' - thus finding the balance between conflicting incommensurable values and dimensions (Munda, 2004). The notion 'optimal' siting, nevertheless, commonly appears in SMCDA papers but should be interpreted as 'suitable' sites that render least level of conflict and highest levels of consensus, and which thereby represent the 'optimal compromise'. What really matters in a multi-criteria framework is the actual democratic process towards consensus since the problem structuring will determine the ultimate result (Munda, 2004). A high level of stakeholder involvement facilitates the SMCDA planning process from the initial problem structuring and throughout the entire decision-making process up to the final decision. Involving stakeholders is important to reach a justifiable decision through a systematic, participatory, transparent and documented process. Moreover, active participation further provides support for the generation and comparison of spatially explicit alternatives. The definition of 'stakeholder' may diverge because it may be difficult to define what constitutes a legitimate stake (Reed et al., 2009). In this paper, we follow the definition of Gorsevski et al. (2013) and consider any individual or group of individuals that are affected by and/or involved in a technical development as primary stakeholder candidates (also called 'agents').

As environmental or societal concerns often cause opposition against the construction of renewable energy facilities at a specific site (IPCC, 2011; Wolsink, 2012), we developed the Consensus-based Siting (ConSite) SMCDA tool suite to map and assess the spatial consequences of planning decisions based on stakeholders' valuation and acceptance of multiple criteria. ConSite supports integrated assessments instead of isolated sectorial environmental and societal impact assessments. Thereby it provides a decision-support planning tool suite that ensures a holistic, democratic and transparent assessment of technological, socioeconomic and environmental perspectives. In this paper, we present the ConSite SMCDA tool suite which is based on current developments in SMCDA for renewable energy development (Pohekar and Ramachandran, 2004; Mateo, 2012) and current developments within stakeholder analysis (Reed et al., 2009) and decision theory (Bottero et al., 2015). ConSite was developed with Model Builder in ArcGIS 10.3 (ESRI, 2015). ConSite is exemplified for the socially acceptable, environmental friendly and cost-effective routing of high-voltage power lines and siting of onshore wind-power plants in central Norway. ConSite helps decisionmakers and planners to dynamically identify suitable areas for development and aid decisions taken with respect to both transparency and re-examination. This demonstrates that the ConSite tool suite can help to operationalise Environmental Impact Assessments (EIA) and Strategic Environmental Assessments (SEA). 


\section{Methodological Framework}

The ConSite SMCDA process is a step-by-step process that enables problem structuring, decision problem formulation and identification of relevant drivers, thematic content and associated criteria, criteria valuation and their relative importance represented as weights. ConSite combines spatial MCDA, dialogue theory and decision theory into one methodological framework adapted for GIS. The methodological framework consists of six sequential and iterative steps - all with a high level of stakeholder involvement - towards a final compromise output (Fig. 1). The output is an inverted suitability map (hereafter called 'conflict' map as it gives an aggregated measure on the spatial distribution of conflicting interests) visualising where the technological development can be best located within the social-ecological-technical conflict landscape (Ostrom, 2009; McGinnis and Ostrom, 2014). A unique 'optimal' solution does not exist, but the most suitable solution should be grounded on stakeholder inputs and one that minimises conflict and maximises consensus. Feedback loops enable continuous improvements of the model and allows transdisciplinary co-learning to take place (Ferretti and Montibeller, 2016). While these modelling steps are being presented slightly
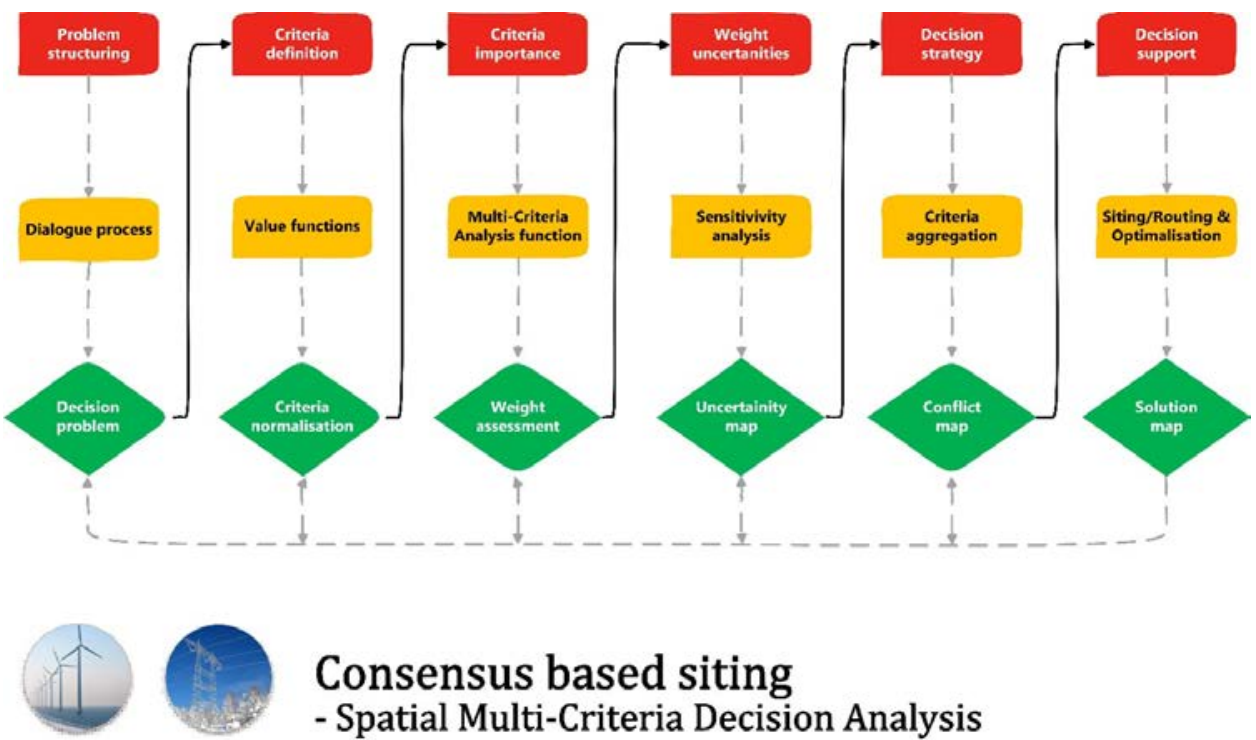

\section{Consensus based siting} - Spatial Multi-Criteria Decision Analysis

Fig. 1. (Color online) The ConSite SMCDA workflow. Stakeholder interaction throughout the SMCDA process is illustrated with solid arrows. If consensus is not reached at any step, the dialogue is looped back to one of the previous steps in order to seek new consensus (grey arrows). The red boxes signify the six steps in the ConSite SMCDA model. The yellow boxes signify the inherent methodological approaches of each step, and the green boxes signify the outcomes of each step. 


\section{F. Hanssen et al.}

different in the SMCDA literature (Hongoh et al., 2011; Gbanie et al., 2013; Ferretti and Montibeller, 2016), our diagram emphasises ConSite as a cyclic evaluation process facilitating a flexible and adaptive SMCDA. The main difference between ConSite and many other SMCDA tools is how ConSite facilitates a high level of stakeholder involvement throughout the entire process (but see Simao et al., 2009). Stakeholders should be involved as active participants with agency. They should not merely be regarded as passive recipients of information, but as local experts with knowledge worthy of inclusion in all steps in the SMCDA. We are convinced that such involvement will give stakeholders ownership and validity to each of the step-wise outputs and the final solution map.

\section{Scoping the problem}

The first step of the ConSite workflow is to define and structure the decision problem. For this purpose, we have recognised and adapted a participatory dialogue process in ConSite based on the Adaptive Environmental Assessment and Management (AEAM) methodology (Holling, 1978). This included the formalisation of a representative group of stakeholders that would be affected by the actual renewable energy construction project (Thomassen et al., 2012a, 2012b). While stakeholder involvement can be organised in many different ways according to the context and the inherent needs, if implemented early in the planning and decision process, participatory dialogue can avoid potential conflicts and increase the public transparency. To optimise the dialogue process, it is important to balance competing interests and, from that, decide who should be involved and how they can contribute. Durham et al. (2014) recommend that dialogue processes address why (i.e. defining the outcomes desired from the engagement process; weighing the criteria to assess agreement and disagreement), who (i.e. identifying the stakeholders necessary for a robust outcome), when (i.e. engagement levels necessary at certain times in the process, also to secure robust outcomes) and how (i.e. finding the best dialogue form to build trust and obtain robust outcomes) to engage stakeholders in order to ensure inclusiveness and enhance legitimacy and societal relevance.

From the prior assessment, invited stakeholders will during one or several dialogue seminar(s) structure the decision problem and identify relevant criteria pertaining to the decision process. The identified criteria (e.g. distance to settlements, visibility in the landscape, migratory corridors, biodiversity hotspots, terrain conditions for construction) are defined during the dialogue seminars. In such cases in which criteria could be interpreted in various ways (e.g. visual impact or biodiversity hotspots), stakeholders were asked to provide spatially explicit proxies for these (e.g. line-of-sight visibility or diversity of bird species). Input 
criteria values can often be derived from peer-reviewed literature describing legal requirements, best practices, expert judgements and/or layman judgements. To ensure that each stakeholder is heard, an additional (anonymised) survey can provide all with the opportunity to adjust and set criteria values after the dialogue seminars. Such surveys also provide the opportunity to derive statistical information (e.g. median, range) from the feedback to map the level of agreement and disagreement among stakeholders as part of a sensitivity analysis.

\section{Normalisation of multiple criteria proxies}

Involved criteria are often multiple and incommensurable because they have different objectives measured along qualitative, quantitative, discrete or continuous measurement scales. To make the different criteria proxies comparable along a common measurement scale, they must be normalised using a value function. Value functions enable stakeholders to set thresholds regarding their degree of acceptance, or lack thereof, in the original units. Value functions were used to normalise all criteria proxy values relative to the stakeholder's degree-of-acceptance into a continuous scale from 0 (low acceptance) to 1 (high acceptance). ConSite allows for the utilisation of different value functions (linear, binary, sigmoid and parabolic) based on fuzzy logic theory (Zadeh, 1965; Klir and Yuan, 1996). The involved criteria should as far as possible also be made comparable at a common spatial scale and resolution. Normalising and comparing criteria proxies mapped at unequal spatial scale and resolutions may blur and deteriorate the final consensus (solution) map.

\section{Multiple criteria weighing}

After the normalisation procedure of the criteria proxy values, the relative weight of every normalised criterion is determined by the stakeholders. Malczewski (1999) outlines four main methods for assigning weights to criteria: (1) ranking methods, in which every criterion under consideration is ranked in the order of the decision-maker's preferences; (2) rating methods, which require the estimation of weights on the basis of a predefined scale; (3) pairwise comparison methods, which involve pairwise comparison to create a ratio matrix and (4) trade-off analysis methods, which make use of direct trade-off assessments between pairs of alternatives. ConSite applies the two latter methods to determine the relative importance (weights) of the individual criteria and to aggregate the different criteria into a 'conflict' map (inverted suitability map). Pairwise comparison used to create a ratio matrix or used in a trade-off analysis has the advantages of providing an organised structure for group discussions and helping the stakeholders to focus on areas of agreement and disagreement when setting criterion weights (Drobne and Lisec, 2009). The analytical hierarchical processes (AHP) decision-making procedure (Saaty, 1987) is used to derive ratio scales from both discrete and continuous paired 


\section{F. Hanssen et al.}

comparisons, and it is a method applicable also for qualitative data, although it may be difficult to subjectively scale a concrete quantitative number for pairwise comparisons without losing some degree of accuracy (Mateo, 2012). Despite this, the way AHP handles multiple qualitative and quantitative criteria has favoured its use as a decision-making method and it has therefore been widely used in renewable energy siting projects (e.g. Al-Shabeeb et al., 2016). AHP is particularly recognised for its justification of decisions in terms of transparency and re-examination (Mateo, 2012).

\section{Spatial sensitivity analysis}

Depending on the level of disagreement among stakeholders and the inherent quality of the background geographical data, uncertainty arises regarding how well the aggregated conflict map depicts the reality and degree of consensus for the given decision problem. The background data quality will in principle have the same impact for all stakeholders and may be limited by the maps available to the decisionmakers. As part of the scoping process, selection criteria should be defined for spatial data to be included, and at which spatial resolution, in the further process. Variation in opinions concerning criteria normalisation and weighing by stakeholders will however be important to visualise in the SMDCA. Various forms of spatial sensitivity analysis have been developed (Chen et al., 2013; Ligmann-Zielinska and Jankowski, 2014), but are generally not a common practice in SMCDA-based siting studies (Crosetto et al., 2000; Ligmann-Zielinska and Jankowski, 2008; Lilburne and Tarantola, 2009; Benke and Pelizaro, 2010; Chen et al., 2011). The simplest and far most frequent implementation of sensitivity analysis is based on the variation of criteria proxy normalisation values and weights to see whether, and how, this significantly modifies the resulting outcome map (Montserrat and Joaquín, 2014). ConSite currently supports only this type of spatial sensitivity analysis.

\section{Criteria aggregation and trade-off analysis}

The next stage is to aggregate the various criteria (by some authors called the evaluation or combination stage). There is a great diversity of methods on how to combine spatial multi-criteria data, but these are usually variants of Boolean overlay operations, weighted linear combination (WLC) (Voogd, 1983) and ordered weighted averaging (OWA) (Yager, 1988). The simplest method is the traditional overlay techniques using Boolean operators. Aggregating conflict areas using the Boolean operators AND and OR implies risk-aversive and risk-taking decision alternatives but without any continuity between them (binary decision alternatives). In addition, AND and OR implies no trade-off.

WLC is an aggregation method that seeks to overcome the lack of sensitivity in traditional Boolean overlay techniques. The WLC aggregation method multiplies each normalised criteria map by its criteria weight and then sums the results 
(Comber et al., 2010). Instead of the hard Boolean decision of assigning absolute low conflict or high conflict to a location for a given criterion, WLC scales the criteria to a particular common range where suitable and unsuitable areas are continuous measures (Sposito et al., 2013). Therefore, WLC is more often used in decision-making processes than the Boolean approaches (Jiang and Eastman, 2000). There are, however, some issues associated with multi-criteria evaluation analyses using WLC approaches. WLC lacks proper capabilities to evaluate decision risk, due to the assumed linearity of scale transformations of criteria and additivity of weight averaging (Malczewski, 2000; Jiang and Eastman, 2000).

OWA can be recognised as a modification of the WLC formula by introducing two different kinds of weights: the criteria weights (also used in WLC) and the order weights. The criterion weights are assigned to the evaluation criteria to indicate their relative importance. The criteria weights $\left(w_{j}\right)$ are applied uniformly: all locations (e.g. pixels) on the $j$ th criterion map are assigned the same weight of $w_{j}$. The order weights are associated with the criterion values on the location-bylocation basis. They are assigned to the ith location's attribute value in decreasing order without considering from which criterion map the value comes (Malczewski, 2006c). The OWA procedure includes the following steps (Comber et al., 2010):

(1) Each criterion is weighted for its relative importance.

(2) An intermediate layer is derived from each criteria map, and the weighted values at each location (pixel) are evaluated and ranked from lowest to highest values.

(3) The order weights are then applied in the following way: the first order weight is applied to the highest value; the second order weight is applied to the next highest value and so on.

OWA has been used in many different GIS applications (Comber et al., 2010; Ahn and Yager, 2014) and provides considerable refinement of the Boolean and WLC approaches. Both WLC and OWA allow for trade-off between different criteria by weighing the normalised criteria according to their relative importance. A low conflict value defined by one criterion with a high weight may be equivalent to a high conflict value in another criterion with a lower weight - thus the former may be compensated by the latter. This capability of compensating a low score for one criterion with a high score for another criterion is known as trade-off or substitutability (Jiang and Eastman, 2000). Trade-offs between criteria depend on, and are controlled by, the weights that are assigned to them. Still, it is important to point out that also OWA has its limitations one should be aware of. Even though a single user may make a conscious risk decision, trade-offs (i.e. balancing a highconflict criterion with a low-conflict criterion using weights) can lead to 


\section{F. Hanssen et al.}

overlooking critical factors and mislead decision-making. This can be overcome by a thorough deliberative process in which the input from stakeholders is combined, evaluated and - if necessary — adjusted. Although the individual-based OWA is bound to overlook some critical factors, participation of different users in a deliberative process enhances the chance that all critical factors will be included in the assessment.

For ConSite, we have implemented both the WLC and OWA for criteria aggregation, risk assessment and trade-off analysis. The introduction of the order weights makes OWA a better aggregation approach than WLC in managing decision risk. The order weights control the degree of risk-aversion or risk-taking one is willing to take, i.e. the position along the first axis in Fig. 2. Risk and trade-off are the two dimensions that define the decision strategy space (as illustrated in the right part of Fig. 2). The Boolean approach (not included in ConSite, but here visualised by grey dots) represents an extreme risk aversion (binary rejection) and extreme risk taking (binary acceptance) as portrayed in Fig. 2. WLC (medium risk and maximum trade-off) is in position 1, whereas positions 2-7 represent different

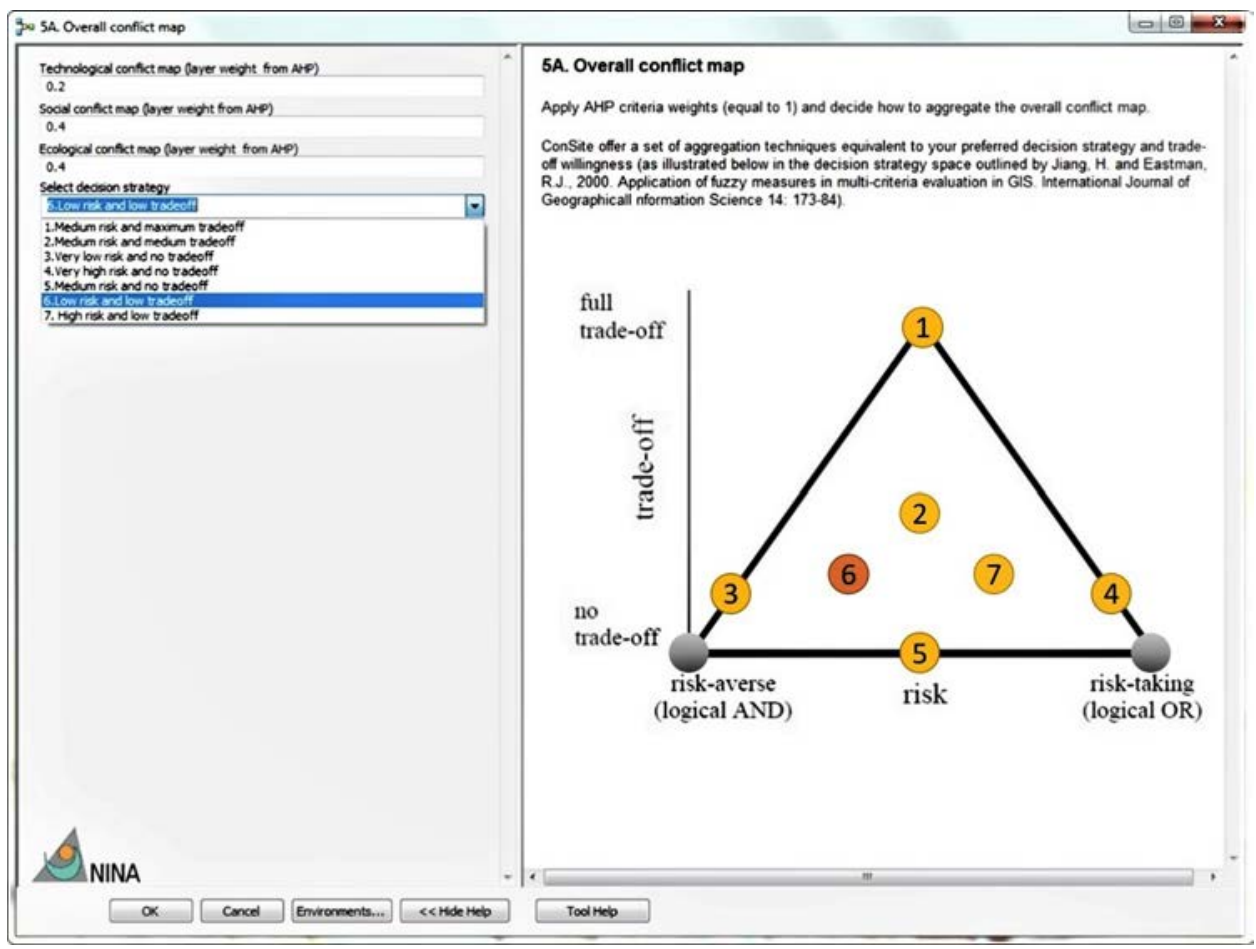

Fig. 2. (Color online) Criteria aggregation using AHP, OWA and a low risk and high trade-off decision strategy to obtain the conflict map (illustration after Jiang and Eastman, 2000). 
OWA-based decision strategies. Position 6 (red dot) represents decision strategy number 6 (low risk and low trade-off).

\section{Siting/routing optimisation}

The ConSite SMCDA suite has currently two modules: ConSite Power-line and ConSite Wind. While these two modules are relatively similar, albeit with potentially different criteria, they have specific methodology for, respectively, routing (i.e. line segments) and siting (i.e. polygons).

Based on the aggregated conflict maps, ConSite Power-line utilises a standard least-cost path (LCP) algorithm (Chang, 2016). An LCP algorithm finds the 'cheapest' path from one point to another over a cost surface (equivalent to our conflict map). The cost surface is a raster map where each cell value defines how "expensive" it is to pass through that cell (Bagli et al., 2011). By generating an accumulated cost surface based on the conflict map, the LCP algorithm identifies the line between two points with the lowest accumulated level of conflict. ConSite Power-line uses LCP analysis to calculate suitable power-line routing and identify project corridor(s) for further impact assessments and detailed planning between predefined locations (e.g. existing transformer and connector stations). ConSite Power-line currently only supports WLC for criteria aggregation, risk assessment and trade-off analysis.

The ConSite Wind module helps to identify suitable areas for wind-power development. First, it computes a conflict map based on a preferred trade-off/risk decision strategy and from this derives a conflict zone map (with inherent conflict statistics). Thereafter, the ConSite Wind module optimises siting and design layout of a wind-power plant based on the maximum allowed conflict level, calculated annual turbine power output (MWh) from local wind resources and preferred wind-power plant size (number of turbines and inter-turbine distance) (for details, see Hanssen et al., 2018). ConSite assumes rectangular wind-power plant sites calculated using the Minimum Bounding Geometry tool in ArcGIS 10.3 (ESRI, 2015) to delineate the areas satisfying the requirements given by the criteria. ConSite Wind supports both AHP, WLC and OWA methodology for criteria aggregation, risk assessment and trade-off analysis.

\section{Implementation Examples for the Siting of Renewable Energy Structures}

\section{Routing of high-voltage power lines}

As an example of routing optimisation, we present an application of ConSite Power-line to validate the construction of a high-voltage power-line routing 


\section{F. Hanssen et al.}

project. With 'validate' we here mean a comparison of the post-construction modelled power-line routing to the constructed power-line routing. We used a subset of the same criteria as those used in the actual EIA made prior to the construction of the existing power line (Table 1). In total, 18 stakeholders who were involved in the EIA process (developers and consultants, national authorities (energy, environment, cultural heritage), regional and local authorities, NGOs (farmers' association, tourism, reindeer management)) and seven experts,

Table 1. Criteria included in the ConSite Power-line routing exemplar.

\begin{tabular}{|c|c|c|c|c|}
\hline \multirow[t]{2}{*}{ Criteria } & \multicolumn{2}{|c|}{ Criteria value } & \multirow[t]{2}{*}{ Criteria weight } & \multirow[t]{2}{*}{ Domain weight } \\
\hline & $\begin{array}{c}\text { Least } \\
\text { acceptable }\end{array}$ & $\begin{array}{c}\text { Most } \\
\text { acceptable }\end{array}$ & & \\
\hline \multicolumn{5}{|l|}{ Distance from: } \\
\hline - Cabins & $500 \mathrm{~m}$ & $1 \mathrm{~km}$ & $20 \%$ & \multirow{14}{*}{$\begin{array}{l}\text { Socio- } \\
\quad \text { economics } \\
40 \%\end{array}$} \\
\hline - Tracks & $500 \mathrm{~m}$ & $1 \mathrm{~km}$ & & \\
\hline $\begin{array}{l}\text { Distance from cultural heritage } \\
\text { sites }\end{array}$ & $200 \mathrm{~m}$ & $500 \mathrm{~m}$ & $10 \%$ & \\
\hline $\begin{array}{l}\text { Distance from cultural } \\
\text { landscapes }\end{array}$ & $300 \mathrm{~m}$ & $2 \mathrm{~km}$ & $15 \%$ & \\
\hline $\begin{array}{l}\text { Distance to densely populated } \\
\text { areas }\end{array}$ & $100 \mathrm{~m}$ & $120 \mathrm{~m}$ & $10 \%$ & \\
\hline Distance to buildings & $75 \mathrm{~m}$ & $150 \mathrm{~m}$ & $20 \%$ & \\
\hline \multicolumn{4}{|l|}{ Distance to domestic reindeer: } & \\
\hline - Breeding areas & $700 \mathrm{~m}$ & $1 \mathrm{~km}$ & \multirow[t]{4}{*}{$10 \%$} & \\
\hline - Tracking routes & $300 \mathrm{~m}$ & $700 \mathrm{~m}$ & & \\
\hline - Winter pastures & $300 \mathrm{~m}$ & $700 \mathrm{~m}$ & & \\
\hline - Reindeer infrastructure & $300 \mathrm{~m}$ & $700 \mathrm{~m}$ & & \\
\hline \multicolumn{4}{|l|}{ Visual impact of power lines: } & \\
\hline - Rural homes & 200 homes & 0 homes & \multirow[t]{2}{*}{$15 \%$} & \\
\hline - Urban homes & 200 homes & 0 homes & & \\
\hline \multicolumn{3}{|l|}{$\begin{array}{l}\text { Power line environmental } \\
\text { stress: }\end{array}$} & & \multirow{7}{*}{ Technology $20 \%$} \\
\hline - Ice load & $20 \mathrm{~kg} / \mathrm{m}$ cable & $0 \mathrm{~kg} / \mathrm{m}$ cable & $20 \%$ & \\
\hline - Wind load & $50 \mathrm{~m} / \mathrm{s}$ & $0 \mathrm{~m} / \mathrm{s}$ & & \\
\hline $\begin{array}{l}\text { Distance from existing roads, } \\
\text { railways and power lines }\end{array}$ & $100 \mathrm{~m}$ & $40 \mathrm{~m}$ & $40 \%$ & \\
\hline \multicolumn{3}{|l|}{$\begin{array}{l}\text { Ground conditions relevant for } \\
\text { pylons: }\end{array}$} & \multirow{3}{*}{$40 \%$} & \\
\hline $\begin{array}{l}\text { - Exclude bogs, mires, water } \\
\text { bodies }\end{array}$ & \multicolumn{2}{|c|}{ Binary YES/NO } & & \\
\hline - Exclude stone avalanche areas & Binary $Y$ & YES/NO & & \\
\hline
\end{tabular}


Table 1. (Continued)

\begin{tabular}{|c|c|c|c|c|}
\hline \multirow[t]{2}{*}{ Criteria } & \multicolumn{2}{|c|}{ Criteria value } & \multirow[t]{2}{*}{ Criteria weight } & \multirow[t]{2}{*}{ Domain weight } \\
\hline & $\begin{array}{c}\text { Least } \\
\text { acceptable }\end{array}$ & $\begin{array}{c}\text { Most } \\
\text { acceptable }\end{array}$ & & \\
\hline $\begin{array}{l}\text { - Exclude snow avalanche } \\
\text { areas }\end{array}$ & \multicolumn{2}{|c|}{ Binary YES/NO } & & \\
\hline - Exclude quick clay areas & \multicolumn{2}{|c|}{ Binary YES/NO } & & \\
\hline Terrain steepness & $30^{\circ}$ & $0^{\circ}$ & & \\
\hline \multicolumn{5}{|l|}{$\begin{array}{l}\text { Distance to protected nature } \\
\text { areas: }\end{array}$} \\
\hline - Nature reserves & $500 \mathrm{~m}$ & $1 \mathrm{~km}$ & $20 \%$ & Ecology $40 \%$ \\
\hline - National parks & $300 \mathrm{~m}$ & $875 \mathrm{~m}$ & & \\
\hline - Protected landscapes & $500 \mathrm{~m}$ & $1 \mathrm{~km}$ & & \\
\hline - Protected water courses & $100 \mathrm{~m}$ & $150 \mathrm{~m}$ & & \\
\hline Distance from wilderness areas & $5 \mathrm{~km}$ & $>5 \mathrm{~km}$ & $20 \%$ & \\
\hline \multicolumn{5}{|l|}{$\begin{array}{l}\text { Distance from important bird } \\
\text { sites: }\end{array}$} \\
\hline $\begin{array}{l}\text { - Nesting sites for gallinaceous } \\
\text { birds }\end{array}$ & $200 \mathrm{~m}$ & $300 \mathrm{~m}$ & $20 \%$ & \\
\hline - Nesting sites for raptors & $750 \mathrm{~m}$ & $1 \mathrm{~km}$ & & \\
\hline - Leks of gallinaceous birds & $300 \mathrm{~m}$ & $500 \mathrm{~m}$ & & \\
\hline $\begin{array}{l}\text { - Resting sites for redlisted } \\
\text { birds }\end{array}$ & $500 \mathrm{~m}$ & $1 \mathrm{~km}$ & & \\
\hline - Wetlands (wading birds) & $500 \mathrm{~m}$ & $1 \mathrm{~km}$ & & \\
\hline \multicolumn{5}{|l|}{ Distance to wild reindeer: } \\
\hline - Breeding areas & $700 \mathrm{~m}$ & $1 \mathrm{~km}$ & $40 \%$ & \\
\hline - Tracking routes & $500 \mathrm{~m}$ & $700 \mathrm{~m}$ & & \\
\hline - Seasonal grazing areas & $500 \mathrm{~m}$ & $1 \mathrm{~km}$ & & \\
\hline
\end{tabular}

altogether representing a wide expertise on societal, ecological and technical issues relating to routing of power lines, were invited to two dialogue seminars. The participants defined relevant themes (e.g. cultural landscapes), sub-themes (e.g. distance to national important cultural landscapes), criteria (e.g. avoid infrastructure close to the cultural landscape) and criteria threshold values (e.g. $>120 \mathrm{~m}$ away from existing infrastructure). As a final step, the different criteria were given a weight of importance compared with the other criteria (more details are described in Thomassen et al., 2012a, 2012b). The power line modelled in ConSite collocated relatively well with the existing power line (Fig. 3) (Hanssen et al., 2014). The modelled power line deviated from the constructed power line 


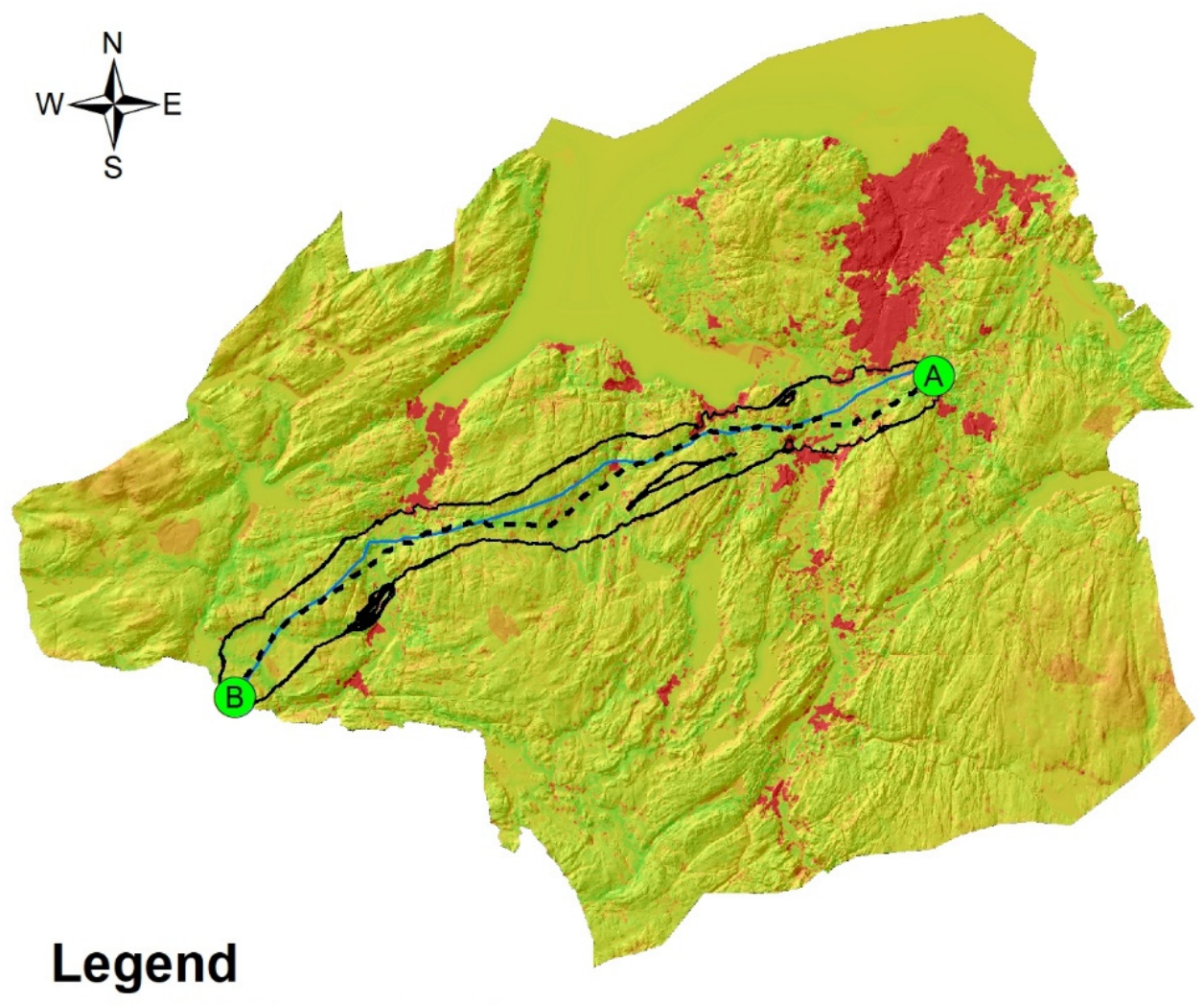

- Actual $420 \mathrm{kV}$ power line path

- - Calculated optimal path

$\sqrt{3}$ Corridor $(0,5$ standard deviations)

High : 0.423618

Low : 0.0324891

Kilometers

Fig. 3. (Color online) The conflict map based on an aggregation of social, technological and ecological criteria maps and the result of processing a least cost path algorithm from A to $\mathrm{B}$. The calculated corridor (black polygon) and optimal power-line path (dotted line) is compared to the existing power-line path (blue line).

from $0.1 \mathrm{~km}$ to $0.85 \mathrm{~km}$; with an average deviation of $0.46 \mathrm{~km}$ and median deviation of $0.2 \mathrm{~km}$ (first and third quartile is $0.1 \mathrm{~km}$ and $0.85 \mathrm{~km}$, respectively).

\section{Siting of wind-power plants}

There exist extensive plans for wind-power development in Norway. However, it is not entirely problem-free to develop wind-power plants, as they may come into 
conflict with environmental, societal and other interests. Currently, there is no national SEA for onshore wind-power development in Norway upon which to base a national plan for (politically decided) areas for development (May, 2011; Thygesen and Agarwal, 2014). Regional plans for wind-power development, however, in part comply to SEA requirements as set out in the EU SEA Directive which Norway signed (May, 2011). A national plan is being developed at the moment, however not strictly following the guidance of the EU SEA Directive. However, county governments are to draw up regional plans to ensure holistic and long-term wind-power development in their region according to the national Planning and Building Act. These regional plans provide guidelines for appropriate planning and site selection of wind-power plants within the county or region. The regional plans focus on identifying and characterising the potential for

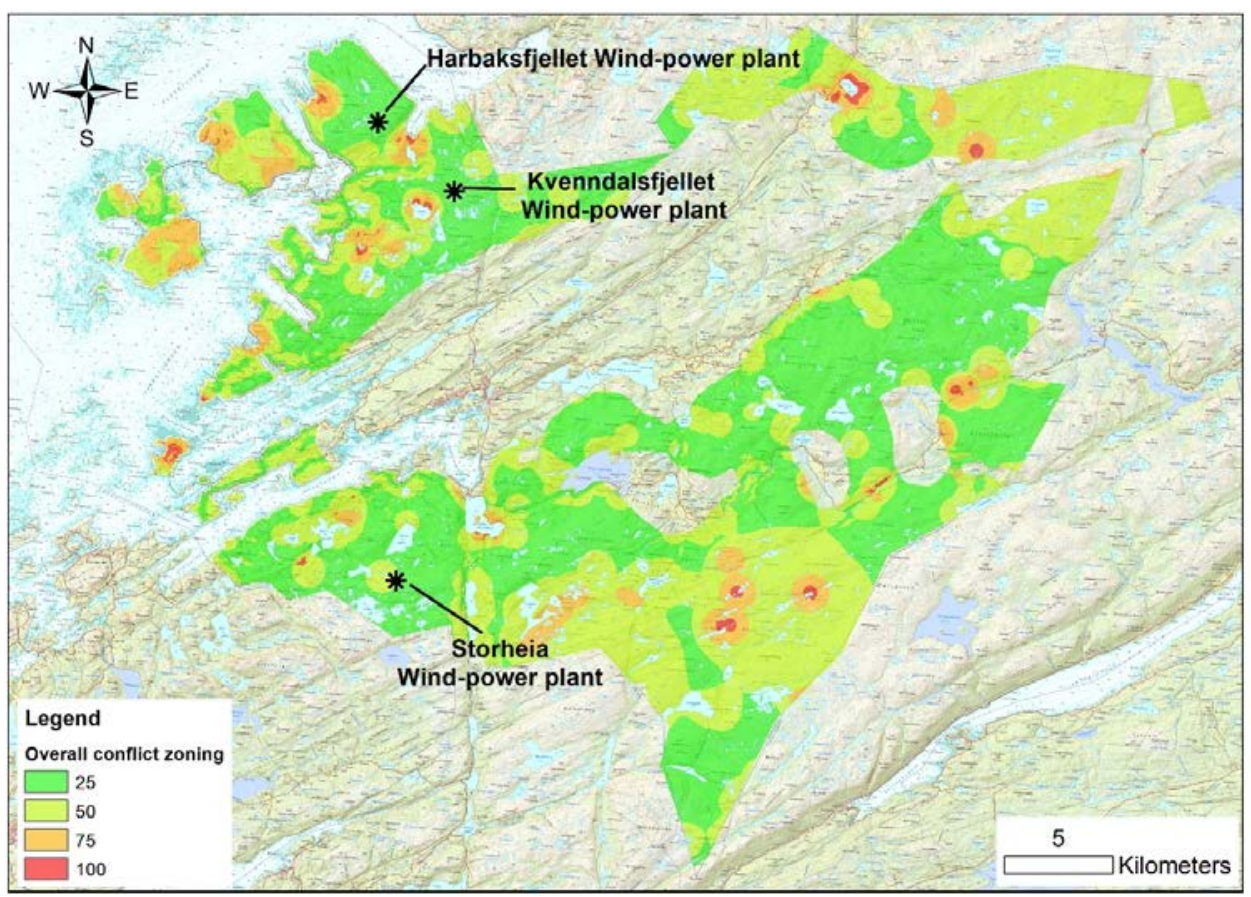

Fig. 4. (Color online) Conflict levels in the Åfjord municipality case study area (based on a low risk and low trade-off decision strategy), in areas with sufficient wind resources, derived from socio-economic, technological and ecological criteria maps. The Harbakfjellet wind-power plant (outlined in red) has a low conflict level and hence a high suitability, based on the applied criteria in this example. Wind-power plants under planning and concession evaluation are outlined in black. 


\section{F. Hanssen et al.}

conflicts and aid the identification of suitable sites for wind power in the region with least societal and environmental conflict per $\mathrm{kWh}$. We applied a selection of relevant criteria derived from the regional plans and valuated and weighted the criteria for a case study example in the Åfjord municipality on the Fosen peninsula, Central Norway, where extensive wind-power development is planned. Within Åfjord municipality, three wind-power plants were consented to be constructed before 2020. Based on the criteria applied in this example, the consented Harbakfjellet (108 MW, $324 \mathrm{GWh}$ ), Kvenndalsfjellet (101 MW, $302 \mathrm{GWh}$ ) and Storheia (288 MW, $864 \mathrm{GWh}$ ) wind-power plants were all delineated as suitable areas using the ConSite Wind module because of these areas' lower level of conflict (Fig. 4). Offsetting the level of conflict to the expected energy production potential at each site, Harbakfjellet wind-power plant came out as being the best site within Åfjord municipality (Fig. 5). This corresponds very well with the given concession at Harbakfjellet.

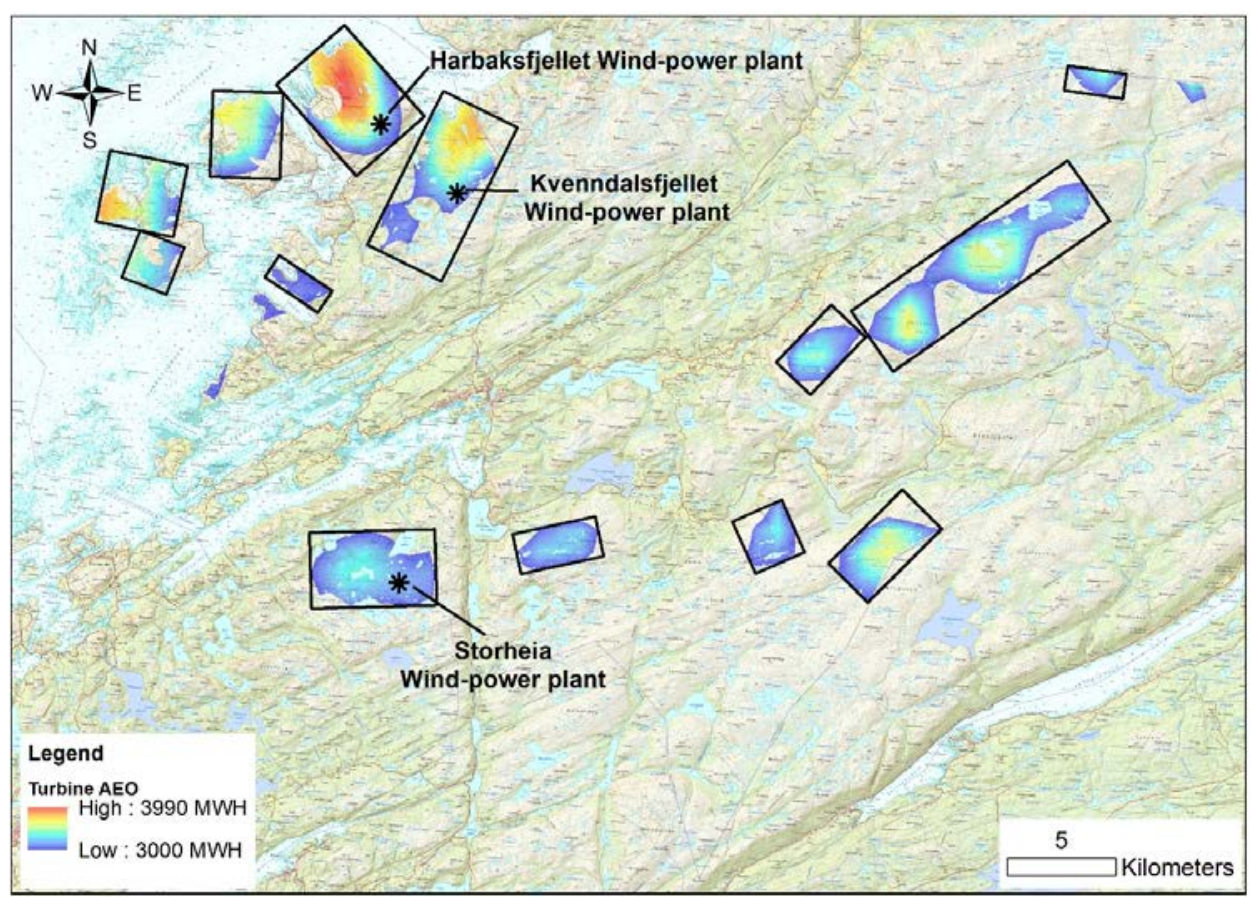

Fig. 5. (Color online) The most suitable areas for wind-power turbine annual energy output (AEO) according to the ConSite tool suite within Åfjord municipality on the Fosen peninsula, Central Norway. Consented wind-power plants are indicated with an asterisk. 
Table 2. Criteria included in the ConSite Wind-power siting exemplar.

\begin{tabular}{|c|c|c|c|c|}
\hline \multirow[t]{2}{*}{ Criteria } & \multicolumn{2}{|c|}{ Criteria value } & \multirow[t]{2}{*}{ Criteria weight } & \multirow[t]{2}{*}{ Domain weight } \\
\hline & $\begin{array}{c}\text { Least } \\
\text { acceptable }\end{array}$ & $\begin{array}{c}\text { Most } \\
\text { acceptable }\end{array}$ & & \\
\hline Required annual wind resources & $4 \mathrm{~m} / \mathrm{s}$ & Max. wind speed & $40 \%$ & Technology $20 \%$ \\
\hline Distance to overhead powerlines & $150 \mathrm{~m}$ & $10 \mathrm{~km}$ & $20 \%$ & \\
\hline Distance to main roads & $100 \mathrm{~m}$ & $300 \mathrm{~m}$ & $30 \%$ & \\
\hline Topographic heterogeneity & $0 \%$ & $20 \%$ & $10 \%$ & \\
\hline Distance to cultural heritage sites & $200 \mathrm{~m}$ & $2.5 \mathrm{~km}$ & $20 \%$ & Social $40 \%$ \\
\hline Distance to cultural landscapes & $1 \mathrm{~km}$ & $5 \mathrm{~km}$ & $10 \%$ & \\
\hline $\begin{array}{l}\text { Distance to settlements and } \\
\text { cabins }\end{array}$ & $300 \mathrm{~m}$ & $1.5 \mathrm{~km}$ & $30 \%$ & \\
\hline $\begin{array}{l}\text { Fragmentation of agricultural } \\
\text { land and commercial forest } \\
\text { land }\end{array}$ & \multicolumn{2}{|c|}{ Binary YES/NO } & $40 \%$ & \\
\hline Distance to nesting raptors & $750 \mathrm{~m}$ & $1 \mathrm{~km}$ & $20 \%$ & Ecology $40 \%$ \\
\hline Distance to shoreline & $100 \mathrm{~m}$ & $>100 \mathrm{~m}$ & $24 \%$ & \\
\hline $\begin{array}{l}\text { Distance to protected nature } \\
\text { areas: }\end{array}$ & & & & \\
\hline - Nature reserves & $500 \mathrm{~m}$ & $1 \mathrm{~km}$ & $27 \%$ & \\
\hline - National parks & $500 \mathrm{~m}$ & $2.5 \mathrm{~km}$ & & \\
\hline - Protected landscape areas & $1 \mathrm{~km}$ & $2.5 \mathrm{~km}$ & & \\
\hline - Protected water catchment areas & $0 \mathrm{~m}$ & $500 \mathrm{~m}$ & & \\
\hline $\begin{array}{l}\text { Distance to unprotected } \\
\text { wilderness }\end{array}$ & $3 \mathrm{~km}$ & $5 \mathrm{~km}$ & $29 \%$ & \\
\hline
\end{tabular}

\section{Discussion}

This paper demonstrates how the ConSite SMCDA tool suite can help to build consensus, optimise spatial planning and improve decision-making processes in the pre-construction phase of high-voltage power line and wind-power plant construction projects. ConSite facilitates stakeholder dialogue and is designed to perform a combination of modern multi-criteria evaluation and decision analysis techniques. More specifically this includes criteria standardisation (fuzzy logic value functions), weighting (analytical hierarchy processing), trade-off and risk assessment (WLC and OWA), spatial sensitivity analysis and optimisation techniques for routing and site selection. Because enhanced functionality inherently also increases complexity, it will be important that stakeholders are guided through 


\section{F. Hanssen et al.}

the dialogue process and will only have to relate to the identification of the decision problem, criteria content and estimation of weights. ConSite is flexible and may be implemented within a range of decision-makers' preferences from different contexts.

Despite scientific advances in SMCDA and Spatial Decision Support Systems during the last decades (Mateo, 2012; Moghadam et al., 2016; Grêt-Regamey et al., 2017), it is our impression that a substantial amount of current spatial decision-making is still based on traditional (and often analogue) land-use planning approaches. SEA and EIA are the most important tools in current spatial decision-making. SEA is a proactive approach at earlier stages of the decisionmaking process for strategic choice (and siting) of alternative developments. SEA thereby sets the framework for future development consent of projects subject to EIA. Although project-based, EIA should include the assessment of a range of alternatives (including the status quo) such as alternative siting. Both represent a systematic process in which relevant information and stakeholder views are collected, documented and presented in a structured way and regarded as an effective planning tool that helps to improve decision-making (Malczewski, 2006a; Snell and Cowell, 2006). However, the increasing complexity of involved criteria and interests in SEAs and EIAs will probably force decision-makers to use more efficient and intelligent approaches. Our experience from meetings with spatial planners and decision-makers in Norway is that they solely use GIS and spatial data for simple spatial analyses and visualisation purposes. The usage of GIS in combination with SMCDA to improve, qualify and aid spatial decision-making is however still lacking. This is probably a matter of prioritisation, but also an indication that there is a great need for a paradigm shift in the educational programs for future spatial planners and decision-makers. We believe that in the coming decades, we will see many changes to our social-ecological-technical landscapes, not in the least due to urbanisation and renewable energy development at the expense of environmental public goods and services. With the current focus on reaching the United Nations' Sustainable Development Goals to facilitate the 'green transition', there will likely be more leverage for transparent and democratic approaches that are able to address complex spatial planning issues.

By aggregating weighted criteria spatially, ConSite contributes to improved visualisation and transparency of complex planning issues to support consensusbased decision-making. The implementation of OWA in ConSite enables visualising the consequences of various trade-off/risk strategies or weight scenarios. Such functionality will be important for addressing complex and more inclusive decision-making processes, by making the consequences of various planning strategies or stakeholder views spatially evident. In this way, the integration of GIS 
and MCDA facilitates participation in the decision-making process by allowing stakeholders to explore different aspects of a decision problem and articulate their preferences (Malczewski, 2006b). Stakeholder dialogue may, however, also be perceived to be too challenging, time-consuming and costly. The group dialogue may be characterised by differences in mandates, conformity pressure, dominating personalities and ambiguous responsibilities, which in some, if not most, cases may stall the decision-making process (Ferretti and Montibeller, 2016). This is probably the main reason why stakeholder involvements are not always fully implemented throughout many spatial planning and decision-making processes. It may therefore be important to identify the intra-relationships between the different stakeholders, which could be done in several ways. Among the more established approaches is to use a stakeholder interest-influence matrix (Mendelow, 1981) or constellation analysis (Bruns et al., 2011; Huesca-Perez et al., 2016). These approaches represent a logical process that categorises stakeholders according to their interest and influence (those who have high power and interest, high power and low interest, low power and high interest and low power and low interest). However, relationships between stakeholders are not static but evolve continuously. In addition to identifying what to observe in stakeholder relationships (such as interest and influence), one should recognise the dynamic nature of stakeholder relationships (Missonier and Loufrani-Fedida, 2014). Stakeholder involvement should by no means be restricted to a small circle of influential stakeholder groups (Junker et al., 2007). To address the inherent uncertainty of variability among stakeholder preferences and the uncertainty of applied decision strategies, future development of ConSite should enable mapping these uncertainties using Monte Carlo simulations and variance-based global sensitivity analysis (Feizizadeh et al., 2015) and performing sensitivity analysis for minimising the probability of making errors in decision-making based on fuzzy-modified AHP (Feizizadeh et al., 2015). This could then result in a map visualising the level of disagreement across the landscape, based on the variance in normalisation values and weights. Although the above outline are more ideas for further development rather than implemented functionality, the already established ConSite dialogue approach helps to gather information about and insights into inherent concerns and priorities. This information is used to establish a consensus-based and transparent knowledge platform, which is paramount for obtaining stakeholder consensus and high-quality decision-making (Owen, 2015).

Although ConSite represents a tool suite that can help finding consensus among stakeholders in siting of renewable energy infrastructure, all methodologies inherently have their limitations. ConSite assumes that stakeholders actively participate in the dialogue process and that the constellation of stakeholders is 


\section{F. Hanssen et al.}

balanced. However, if some sectoral representatives frustrate the dialogue or even refuse to become involved, the ultimate decision may not represent their views, which they thereafter can oppose politically. There should as such also be a societal consensus on whether or not to use a tool suite as ConSite in the first place. This can be realised by the relevant planning authorities by employing it as a standard. Regardless of this, any GIS tool requires that the relevant criteria actually can be mapped and that the extent, accuracy and resolution of the spatial data are deemed sufficient. Criteria that cannot be mapped, either directly or through proxies, cannot be considered. Criteria may function across a range of spatial scales. This necessitates the incorporation of multiple-scale approaches through the involvement of stakeholders at different institutional scales and the consequent setting of threshold values and weights at appropriate biophysical scales (de Groot et al., 2010). Thirdly, associated criteria that are linked to a specific area or regularly appear together repeatedly in space and time may form bundles of associated criteria (Berry et al., 2016). Such bundles of spatially correlated criteria are indicative of the multi-functionality of an area. This, however, also means that multi-functional areas likely result in higher conflict levels due to this collocation which will be of relevance from an SEA/EIA perspective with respect to cumulative effects. ConSite currently associates each criterion to, respectively, the socio-economic, technology and ecology domain and hierarchically aggregates criteria within domains and thereafter across domains. Although not yet implemented, considering criteria bundles may reduce the risk over overseeing specific key criteria, but may also serve the interests of some stakeholders above others, leading to issues in distributive impacts, legitimacy and power asymmetries (Berry et al., 2016). Integrating area multi-functionality or cumulative effects is still quite challenging and requires methods for identifying associations and spatial coincidence of criteria bundles using, for example, multivariate techniques (Berry et al., 2016).

A potential pitfall during the scoping process is the inclusion of both cause and effect criteria, which may inflate a potential conflict due to double counting. For instance, the financial consequences of constructing within highly productive forest sites should preferably not be included; rather constructing at sites of highly productive forest should be set as less acceptable. While financial cost-benefit assessments are currently the most important rationale for decision-making, we think it is better to base decisions on the actual biophysical values rather than on their monetary proxies. Although a number of economic criteria can be spatially represented, beyond fixed prices (e.g. home sale prices, price of land) valuation proxies will have to be used. Monetary valuation has been developed for ecosystem and cultural services (Gómez-Baggethun et al., 2010); however, there are 
many inherent controversies making a complete representation of economic criteria hard to achieve (Spash and Aslaksen, 2015). Still, applying the ecosystem service framework (de Groot et al., 2010), the benefits humans derive from the natural environment and ecosystems may further strengthen ConSite (for proposed approach, see Hanssen et al., 2018) as it may better visualise the costs and benefits for a variety of public goods and services across the landscape (Geneletti, 2011). This may be of special importance in urban settings in which the pressure on natural features due to anthropogenic development is intense. The ConSite tool suite can thereby contribute to siting of industrial and housing areas or alternatively routing of green corridors in urban areas.

\section{Conclusions}

The rapid and large-scale development of renewable energy worldwide places simultaneously more pressure on society and the natural environment. Although there is considerable support for renewable energy development, its expansion also causes several concerns which traditional land-use planning may have limited capacity to address adequately. In regional planning, environmental and societal concerns of renewable energy development and transmission lines need somehow to be offset against technological and socio-economic benefits within a spatial context. SMCDA tools can help to identify suitable development areas and render feedback on the conflict potential and its inherent conflict levels. The ConSite tool suite was developed to support integrated and participatory assessment of renewable energy siting within a spatial context. ConSite build upon active stakeholder dialogue and employs analytical hierarchical processing and ordered weighted assessment algorithms for aggregation and trade-off analysis. ConSite allows for visualising the consequences of various trade-off/risk decision strategies or weight scenarios. In this way, the integration of GIS and MCDA facilitates participation in complex decision-making processes by allowing stakeholders to explore different aspects of a decision problem and to articulate their preferences. ConSite has been applied to the routing of energy transmission lines and the siting of onshore wind-power plants, but can also be modified to aid planning decisions of technical or ecological infrastructures (e.g. aquaculture and ecological corridors).

\section{Acknowledgments}

ConSite has been conceived and developed as part of the research project 'Optimal design and routing of power lines in ecological, technical and economic 
perspectives' (OPTIPOL) funded by the Research Council of Norway, Statkraft, Statnett, the Norwegian Water Resources and Energy Directorate, the Norwegian Environment Agency and the Norwegian Electricity Industry Association (Energy Norway). We wish also to acknowledge the Centre for Environmental Design of Renewable Energy (CEDREN), founded by the Research Council of Norway and energy companies, for supporting the further development of ConSite Wind.

\section{References}

Afshari, AR and RM Yusuff (2012). A review of spatial multi criteria decision making. In 6th Int. Symp. Advances in Science and Technology, pp. 1-9. Kuala Lumpur, Malaysia: Khavaran Institute of Higher Education.

Ahn, BS and RR Yager (2014). The use of ordered weighted averaging method for decision making under uncertainty. International Transactions in Operational Research, 21, 247-262.

Al-Shabeeb, AR, R Al-Adamat and A Mashagbah (2016). AHP with GIS for a preliminary site selection of wind turbines in the north west of Jordan. International Journal of Geosciences, 7, 1208-1221.

Araneo, R, S Celozzi and C Vergine (2015). Eco-sustainable routing of power lines for the connection of renewable energy plants to the Italian high-voltage grid. International Journal of Energy and Environmental Engineering, 6, 9-19.

Aydin, NY, E Kentel and S Duzgun (2010). GIS-based environmental assessment of wind energy systems for spatial planning: A case study from Western Turkey. Renewable and Sustainable Energy Reviews, 14, 364-373.

Baban, SMJ and T Parry (2001). Developing and applying a GIS-assisted approach to locating wind farms in the UK. Renewable Energy, 24, 59-71.

Bagli, S, D Geneletti and F Orsi (2011). Routeing of power lines through least-cost path analysis and multicriteria evaluation to minimise environmental impacts. Environmental Impact Assessment Review, 31, 234-239.

Benke, KK and C Pelizaro (2010). A spatial-statistical approach to the visualisation of uncertainty in land suitability analysis. Journal of Spatial Science, 55, 257-272.

Berry, P, F Turkelboom, W Verheyden and B Martín-López (2016). Ecosystem services bundles. In OpenNESS: Operationalisation of Natural Capital and Ecosystem Services. Ecosystem Services Reference Book, M Potschin-Young and K Jax (eds.), ECNC-European Centre for Nature Conservation. http://www.openness-project.eu/ library/reference-book/sp-ES-bundles.

Bottero, M, V Ferretti, JR Figueira, S Greco and B Roy (2015). Dealing with a multiple criteria environmental problem with interaction effects between criteria through an extension of the Electre III method. European Journal of Operational Research, 245, $837-850$. 
Bright, J, R Lanyston, R Bullman, R Evans, S Gardner and J Pearce-Higgins (2008). Map of bird sensitivities to wind farms in Scotland: A tool to aid planning and conservation. Biological Conservation, 141, 2342-2356.

Bruns, E, D Ohlhorst, B Wenzel and J Köppel (2011). Renewable Energies in Germany's Electricity Market - A Biography of the Innovation Process. Dordrecht, The Netherlands: Springer.

Carrete, M, JA Sanchez-Zapata, JR Benitez, M Lobon, F Montoya and JA Donazar (2012). Mortality at wind-farms is positively related to large-scale distribution and aggregation in griffon vultures. Biological Conservation, 145, 102-108.

Chang, K-T (2016). Introduction to Geographic Information System, 8th Ed. Boston: Mc Graw Hill.

Chen, H, MD Wood, C Linstead and E Maltby (2011). Uncertainty analysis in a GISbased multi-criteria analysis tool for river catchment management. Environmental Modelling and Software, 26, 395-405.

Chen, Y, J Yu and S Khan (2013). The spatial framework for weight sensitivity analysis in AHP-based multi-criteria decision making. Environmental Modelling and Software, 48, 129-140.

Ciaccia, G, N Doni and F Fontini (2010). Auctioning wind power sites when environmental quality matters. Energy Policy, 38, 1734-1740.

Cole, SG (2011). Wind power compensation is not for the birds: An opinion from an environmental economist. Restoration Ecology, 19, 147-153.

Comber, A, S Carver, S Fritz, R McMorran, J Washtell and P Fisher (2010). Different methods, different wilds: Evaluating alternative mappings of wildness using fuzzy MCE and Dempster-Shafer MCE. Computers, Environment and Urban Systems, 34, $142-152$.

Crosetto, M, S Tarantola and A Saltelli (2000). Sensitivity and uncertainty analysis in spatial modelling based on GIS. Agriculture, Ecosystems and Environment, 81, 71-79.

de Groot, RS, R Alkemade, L Braat, L Hein and L Willemen (2010). Challenges in integrating the concept of ecosystem services and values in landscape planning, management and decision making. Ecological Complexity, 7, 260-272.

Drobne, S and A Lisec (2009). Multi-attribute decision analysis in GIS: Weighted linear combination and ordered weighted averaging. Informatica, 33, 459-474.

Durham, E, H Baker, M Smith, E Moore and V Morgan (2014). The BiodivERsA Stakeholder Engagement Handbook. 108. Paris, France: BiodivERsA.

Enevoldsen, P and BK Sovacool (2016). Examining the social acceptance of wind energy: Practical guidelines for onshore wind project development in France. Renewable and Sustainable Energy Reviews, 53, 178-184.

ESRI (2015). ArcGIS. Advanced version 10.3. Environmental Systems Research Institute (ESRI), Redlands, CA.

Fargione, J, J Kiesecker, MJ Slaats and S Olimb (2012). Wind and wildlife in the Northern great plains: Identifying low-impact areas for wind development. PLOS ONE, 7, e41468. 


\section{F. Hanssen et al.}

Feizizadeh, B, K Omrani and FB Aghdam (2015). Fuzzy analytical hierarchical process and spatially explicit uncertainty analysis. GI Forum - Journal for Geographic Information Science. doi: 10.1553/giscience2015s72, 72-80.

Ferretti, V and G Montibeller (2016). Key challenges and meta-choices in designing and applying multi-criteria spatial decision support systems. Decision Support Systems, 84, 41-52.

Gbanie, SP, PB Tengbe, JS Momoh, J Medo and VTS Kabba (2013). Modelling landfill location using geographic information systems (GIS) and multi-criteria decision analysis (MCDA): Case study Bo, Southern Sierra Leone. Applied Geography, 36, 3-12.

Geneletti, D (2011). Reasons and options for integrating ecosystem services in strategic environmental assessment of spatial planning. International Journal of Biodiversity Science, Ecosystem Services and Management, 7, 143-149.

Gómez-Baggethun, E, R de Groot, PL Lomas and C Montes (2010). The history of ecosystem services in economic theory and practice: From early notions to markets and payment schemes. Ecological Economics, 69, 1209-1218.

Gorsevski, PV, SC Cathcart, G Mirzaei, MM Jamali, X Ye and E Gomezdelcampo (2013). A group-based spatial decision support system for wind farm site selection in Northwest Ohio. Energy Policy, 55, 374-385.

Grêt-Regamey, A, J Altwegg, EA Sirén, MJ van Strien and B Weibel (2017). Integrating ecosystem services into spatial planning - A spatial decision support tool. Landscape and Urban Planning, 165, 206-219.

Hanssen, F, R May, J van Dijk, BG Stokke and M De Stefano (2018). Spatial MultiCriteria Decision Analysis (SMCDA) toolbox for Consensus-based Siting of Powerlines and Wind-power plants (Con-Site). 42. Trondheim, Norway: Norwegian Institute for Nature Research.

Hanssen, FO, RF May, J Thomassen and KM Bevanger (2014). A least cost path (LCP) toolbox for optimal routing of high voltage power lines for a sustainable future. In 10th Int. Symp. Environmental Concerns in Rights-of-Way Management, GJ Doucet (ed.), pp. 181-186. Champaign, IL: USA Utility Arborist Association.

Holling, CS (1978). Adaptive Environmental Assessment and Management. Chichester, UK: John Wiley \& Sons.

Hongoh, V, AG Hoen, C Aenishaenslin, J-P Waaub, D Bélanger and P Michel (2011). Spatially explicit multi-criteria decision analysis for managing vector-borne diseases. International Journal of Health Geographics, 10, 70.

Huesca-Perez, ME, C Sheinbaum-Pardo and J Koppel (2016). Social implications of siting wind energy in a disadvantaged region - The case of the Isthmus of Tehuantepec, Mexico. Renewable and Sustainable Energy Reviews, 58, 952-965.

IPCC (2011). Intergovernmental Panel on Climate Change (IPCC) Special Report on Renewable Energy Sources and Climate Change Mitigation. Cambridge, UK.

Jiang, H and JR Eastman (2000). Application of fuzzy measures in multi-criteria evaluation in GIS. International Journal of Geographical Information Science, 14, 173184. 
Junker, B, M Buchecker and U Müller-Böker (2007). Objectives of public participation: Which actors should be involved in the decision making for river restorations? Water Resources Research, 43. doi: 10.1029/2006WR005584.

Klir, GJ and B Yuan (1996). Fuzzy Sets, Fuzzy Logic, and Fuzzy Systems: Selected Papers by Lotfi A. Zadeh. River Edge, NJ, USA: World Scientific Publishing.

Lempert, RJ and MT Collins (2007). Managing the risk of uncertain threshold responses: Comparison of robust, optimum, and precautionary approaches. Risk Analysis, 27, 1009-1026.

Liechti, F, J Guelat and S Komenda-Zehnder (2013). Modelling the spatial concentrations of bird migration to assess conflicts with wind turbines. Biological Conservation, 162, 24-32.

Ligmann-Zielinska, A and P Jankowski (2008). A framework for sensitivity analysis in spatial multiple criteria evaluation. In Geographic Information Science: 5th Int. Conf., GIScience 2008, Park City, UT, USA, 23-26 September 2008, TJ Cova, HJ Miller, K Beard, AU Frank and MF Goodchild (eds.), pp. 217-233. Berlin, Heidelberg: Springer Berlin Heidelberg.

Ligmann-Zielinska, A and P Jankowski (2014). Spatially-explicit integrated uncertainty and sensitivity analysis of criteria weights in multicriteria land suitability evaluation. Environmental Modelling and Software, 57, 235-247.

Lilburne, L and S Tarantola (2009). Sensitivity analysis of spatial models. International Journal of Geographical Information Science, 23, 151-168.

Luthi, S and T Prassler (2011). Analyzing policy support instruments and regulatory risk factors for wind energy deployment - A developers' perspective. Energy Policy, 39, 4876-4892.

Malczewski, J (1999). GIS and Multicriteria Decision Analysis. New York: John Wiley \& Sons.

Malczewski, J (2000). On the use of weighted linear combination method in GIS: Common and best practice approaches. Transactions in GIS, 4, 5-22.

Malczewski, J (2006a). GIS-based multicriteria decision analysis: A survey of the literature. International Journal of Geographical Information Science, 20, 703-726.

Malczewski, J (2006b). Multicriteria decision analysis for collaborative GIS. In Collaborative Geographic Information Systems, S Balram and S Dragicevic (eds.), pp. 167-185. Hershey/London: Idea Group Publishing.

Malczewski, J (2006c). Ordered weighted averaging with fuzzy quantifiers: GIS-based multicriteria evaluation for land-use suitability analysis. International Journal of Applied Earth Observation and Geoinformation, 8, 270-277.

Malczewski, J and C Rinner (2015). Multicriteria Decision Analysis in Geographic Information Science. New York/Heidelberg/Dordrecht/London: Springer.

Mateo, JRSC (2012). Multi-Criteria Analysis in the Renewable Energy Industry. Green Energy and Technology. London: Springer.

May, R (2011). Strategisk konsekvensutredning for landbasert vindkraft. En evaluering av regionale planer for vindkraft. 34. Trondheim, Norway: NINA. 


\section{F. Hanssen et al.}

May, R (2017). Mitigation options for birds. In Wildlife and Windfarms: Conflicts and Solutions. Volume 2: Onshore Solutions, M Perrow (ed.), pp. 124-145. Exeter, UK: Pelagic Publishing.

McGinnis, MD and E Ostrom (2014). Social-ecological system framework: Initial changes and continuing challenges. Ecology and Society, 19, 30.

McLachlan, C (2009). 'You don't do a chemistry experiment in your best China': Symbolic interpretations of place and technology in a wave energy case. Energy Policy, 37, 5342-5350.

McWilliam, MK, GC van Kooten and C Crawford (2012). A method for optimizing the location of wind farms. Renewable Energy, 48, 287-299.

Mendelow, AL (1981). Environmental scanning: The impact of the stakeholder concept. In ICIS 1981 Proceedings. Paper 20. http://aisel.aisnet.org/icis1981/20.

Missonier, S and S Loufrani-Fedida (2014). Stakeholder analysis and engagement in projects: From stakeholder relational perspective to stakeholder relational ontology. International Journal of Project Management, 32, 1108-1122.

Moghadam, ST, C Delmastro, P Lombardi and SP Corgnati (2016). Towards a new integrated spatial decision support system in urban context. Procedia - Social and Behavioral Sciences, 223, 974-981.

Molnarova, K, P Sklenicka, J Stiborek, K Svobodova, M Salek and E Brabec (2012). Visual preferences for wind turbines: Location, numbers and respondent characteristics. Applied Energy, 92, 269-278.

Montserrat, GD and BS Joaquín (2014). Sensitivity analysis in multicriteria spatial decision-making: A review, human and ecological risk assessment. An International Journal, 10(6), 1173-1187.

Munda, G (2004). Social multi-criteria evaluation: Methodological foundations and operational consequences. European Journal of Operational Research, 158, 662-677.

Ostrom, E (2009). A general framework for analyzing sustainability of social-ecological systems. Science, 325, 419-422.

Owen, D (2015). Collaborative decision making. Decision Analysis, 12, 29-45.

Pedersen, E, F van den Berg, R Bakker and J Bouma (2009). Response to noise from modern wind farms in The Netherlands. Journal of the Acoustical Society of America, 126, 634-643.

Piegat, A and W Sałabun (2012). Nonlinearity of human multi-criteria in decision-making. Journal of Theoretical and Applied Computer Science, 6, 36-49.

Pohekar, SD and M Ramachandran (2004). Application of multi-criteria decision making to sustainable energy planning - A review. Renewable and Sustainable Energy Reviews, 8, 365-381.

Ramirez-Rosado, IJ, E Garcia-Garridoa, LA Fernandez-Jimenez, PJ Zorzano-Santamaria, C Monteiro and V Miranda (2008). Promotion of new wind farms based on a decision support system. Renewable Energy, 33, 558-566.

Reed, MS, A Graves, N Dandy, H Posthumus, K Hubacek, J Morris, C Prell, CH Quinn and LC Stringer (2009). Who's in and why? A typology of stakeholder analysis 
methods for natural resource management. Journal of Environmental Management, 90, 1933-1949.

Rist, L, A Felton, L Samuelsson, C Sandstrom and O Rosvall (2013). A new paradigm for adaptive management. Ecology and Society, 18.

Saaty, RW (1987). The analytic hierarchy process - What it is and how it is used. Mathematical Modelling, 9, 161-176.

Schafer, JG and CT Gallemore (2016). Biases in multicriteria decision analysis: The case of environmental planning in Southern Nevada. Environment and Planning C: Government and Policy, 34, 1652-1675.

Simao, A, PJ Densham and MM Haklay (2009). Web-based GIS for collaborative planning and public participation: An application to the strategic planning of wind farm sites. Journal of Environmental Management, 90, 2027-2040.

Snell, T and R Cowell (2006). Scoping in environmental impact assessment: Balancing precaution and efficiency? Environmental Impact Assessment Review, 26, 359-376.

Spash, CL and I Aslaksen (2015). Re-establishing an ecological discourse in the policy debate over how to value ecosystems and biodiversity. Journal of Environmental Management, 159, 245-253.

Sposito, V, R Faggian, H Romeijn and M Downey (2013). Expert systems modeling for assessing climate change impacts and adaptation in agricultural systems at regional level. Open Journal of Applied Sciences, 3, 369-380.

Tellería, JL (2008). Wind power plants and the conservation of birds and bats in Spain: A geographical assessment. Biodiversity and Conservation, 18, 1781-1791.

Thomassen, J, F Hanssen, R May and K Bevanger (2012a). OPTIPOL Least Cost Path dialog 2. Rapport fra dialogseminar 2 - kriterier og kriterieverdier i OPTIPOL-LCP versjon 1.0. 43. Trondheim, Norway: Norwegian Institute for Nature Research.

Thomassen, J, F Hanssen, R May and K Bevanger (2012b). Optipol Least Cost Path dialog. Rapport fra dialogseminar om tema, deltema og kriterier i Optipol-LCP versjon 1.0. 48. Trondheim, Norway: Norwegian Institute for Nature Research.

Thygesen, J and A Agarwal (2014). Key criteria for sustainable wind energy planning Lessons from an institutional perspective on the impact assessment literature. Renewable and Sustainable Energy Reviews, 39, 1012-1023.

Tsoutsos, T, I Tsitoura, D Kokologos and K Kalaitzakis (2015). Sustainable siting process in large wind farms case study in Crete. Renewable Energy, 75, 474-480.

van Haaren, R and V Fthenakis (2011). GIS-based wind farm site selection using spatial multi-criteria analysis (SMCA): Evaluating the case for New York State. Renewable and Sustainable Energy Reviews, 15, 3332-3340.

Voivontas, D, D Assimacopoulos, A Mourelatos and J Corominas (1998). Evaluation of renewable energy potential using a GIS decision support system. Renewable Energy, $13,333-344$.

Voogd, H (1983). Multi-Criteria Evaluations for Urban and Regional Planning. London: Pion. 
Wolsink, M (2007). Planning of renewables schemes: Deliberative and fair decisionmaking on landscape issues instead of reproachful accusations of non-cooperation. Energy Policy, 35, 2692-2704.

Wolsink, M (2012). Wind power: Basic challenge concerning social acceptance. In Encyclopedia of Sustainability Science and Technology, RA Meyers (ed.), pp. 12218-12254. New York, USA: Springer-Verlag.

Yager, RR (1988). On ordered weighted averaging aggregation operators in multicriteria decisionmaking. IEEE Transactions on Systems, Man, and Cybernetics, 18, 183-190.

Zadeh, LA (1965). Fuzzy sets. Information and Control, 8, 338-353.

Zangl, H, T Bretterklieber and G Brasseur (2008). Energy harvesting for online condition monitoring of high voltage overhead power lines. In 2008 IEEE Instrumentation and Measurement Technology Conf., pp. 1364-1369. 